\section{EFFECT OF AMINO ACIDS ON THE BIOSYNTHESIS OF $\beta$-AMINO ACIDS, CONSTITUENTS OF BACILLOMYCINS F}

\section{F. BESSON and M. L. Hourdou}

Laboratoire de Biochimie Microbienne, Université Claude Bernard,

Lyon I, 43 Boulevard du 11 Novembre 1918, 69622 Villeurbanne Cedex, France

(Received for publication July 24, 1986)

Bacillomycins F, antibiotics of the iturin group, are produced by Bacillus subtilis $\mathrm{I164}^{1}$. Their chemical structures have been determined $^{2)}$; they differ in the nature of the carbon chain of $\beta$-amino acids (Fig. 1). Such $\beta$-amino acids have been isolated only from antibiotics of the iturin group ${ }^{3,4)}$.

Factors affecting the production of bacillomycin $\mathrm{L}$ have been studied $^{5)}$. Several amino acids have been found to increase the production of this antibiotic but their effect on the biosynthesis of $\beta$-amino acids have not been determined.

In this paper, we describe the effect of leucine, isoleucine, valine and threonine on the production of bacillomycins $F$ and on the nature of the carbon chain of the $\beta$-amino acid constituents of bacillomycins $\mathrm{F}$.

B. subtilis 1164 was grown in the medium of LANDY et al ${ }^{8)}$ containing $\mathrm{D}, \mathrm{L}$-threonine, valine,
Fig. 1. Structure of bacillomycins F.

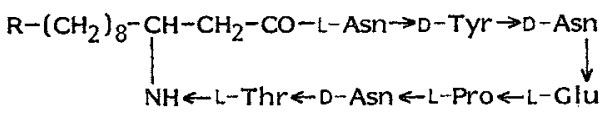

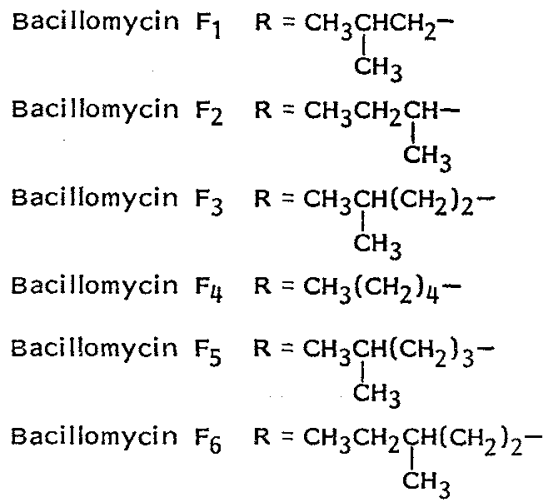

leucine or isoleucine at various concentrations. Culture conditions were as described previously ${ }^{1)}$ and the production of bacillomycins $F$ was determined by $\beta$-amino acids titration ${ }^{5)}$. The effects of different amino acids on bacillomycin $F$ production are summarized in Table 1. Amino acids which had the more positive effect on antibiotic synthesis were valine and isoleucine, which are not present in bacillomycins F. An unexpected result was the absence of increased bacillomycin $F$ production in the presence of threonine, a constituent of the antibiotics.

Table 1. Effect of amino acids on the production of bacillomycin $F$.

\begin{tabular}{lcccc}
\hline \multirow{2}{*}{$\begin{array}{c}\text { Amino acid } \\
\text { added }\end{array}$} & $\begin{array}{c}\text { Concentration } \\
(\mathrm{g} / \text { /iter })\end{array}$ & $\begin{array}{c}\text { Growth } \\
(\text { OD at } 600 \mathrm{~nm})\end{array}$ & $\mu \mathrm{M}$ & $\mu$ mol/g of dry cells \\
\cline { 4 - 5 } None & & 8.1 & 17 & 11 \\
D,L-Valine & 1 & 7.9 & 45 & 26 \\
& 2 & 7.6 & 65 & 38 \\
& 4 & 8.9 & 70 & 40 \\
D,L-Leucine & 8 & 10.2 & 20 & 9 \\
& 1 & 6.9 & 17 & 10 \\
& 2 & 6.6 & 15 & 8 \\
D,L-Isoleucine & 4 & 7.3 & 17 & 7 \\
& 8 & 7.1 & 15 & 50 \\
& 1 & 6.4 & 75 & 46 \\
D,L-Threonine & 2 & 6.5 & 69 & 39 \\
& 4 & 6.9 & 77 & 40 \\
& 8 & 6.2 & 72 & 13 \\
& 2 & 8.7 & 13 & 12 \\
\hline
\end{tabular}


Table 2. Effect of amino acids on the nature of the carbon chain of the constitutive $\beta$-amino acids.

\begin{tabular}{|c|c|c|c|c|c|c|c|}
\hline \multirow{2}{*}{$\begin{array}{c}\text { Amino acid } \\
\text { added }\end{array}$} & \multirow{2}{*}{$\begin{array}{l}\text { Concen- } \\
\text { tration } \\
\text { (g/liter) }\end{array}$} & iso- $\mathrm{C}_{15}{ }^{*}$ & anteiso- $\mathrm{C}_{13}$ & $i s o-\mathrm{C}_{10}$ & $n-C_{16}$ & iso- $\mathrm{C}_{17}$ & anteiso- $\mathrm{C}_{17}$ \\
\hline & & \multicolumn{6}{|c|}{$\%$} \\
\hline None & & 7 & 1 & $\overline{49}$ & 3 & 12 & 27 \\
\hline \multirow[t]{4}{*}{$\mathrm{D}, \mathrm{L}$-Valine } & 1 & & & 83 & & 4 & 12 \\
\hline & 2 & & & 91 & & & 9 \\
\hline & 4 & & & 90 & & & 10 \\
\hline & 8 & & & 90 & & & 9 \\
\hline \multirow[t]{4}{*}{$\mathrm{D}, \mathrm{L}$-Leucine } & 1 & 30 & & 32 & & 16 & 22 \\
\hline & 2 & 24 & & 28 & & 29 & 19 \\
\hline & 4 & 21 & & 25 & & 26 & 28 \\
\hline & 8 & 35 & & 21 & & 21 & 22 \\
\hline \multirow[t]{4}{*}{ D,L-Isoleucine } & 1 & & & 14 & & & 86 \\
\hline & 2 & & 7 & 8 & & & 85 \\
\hline & 4 & & 6 & 6 & & & 88 \\
\hline & 8 & & 6 & 4 & & & 90 \\
\hline \multirow[t]{3}{*}{$\mathrm{D}, \mathrm{L}-\mathrm{Th}$ reonine } & 2 & 1 & 7 & & & & 91 \\
\hline & 4 & 5 & 52 & & & & 43 \\
\hline & 8 & 4 & 62 & & & & 33 \\
\hline
\end{tabular}

* iso- $\mathrm{C}_{15}: 3$-Amino-13-methyltetradecanoic acid, anteiso- $\mathrm{C}_{15}: 3$-amino-12-methyltetradecanoic acid, iso$\mathrm{C}_{18}$ : 3-amino-14-methylpentadecanoic acid, $n$ - $\mathrm{C}_{16}: 3$-aminohexadecanoic acid, iso- $\mathrm{C}_{17}$ : 3-amino-15methylhexadecanoic acid, anteiso- $\mathrm{C}_{17}: 3$-amino-14-methylhexadecanoic acid.

Fig. 2. Comparison of the effect of various amino acids on the nature of $\beta$-amino acids and cellular fatty acids.

Effect of valine (a) on iso- $\mathrm{C}_{14}(O)$ and iso- $\mathrm{C}_{16}(\boldsymbol{O}) \beta$-amino acids, iso- $\mathrm{C}_{14}(\triangle)$ and iso- $\mathrm{C}_{18}(\Delta)$ fatty acids.

Effect of leucine (b) on iso- $\left(\mathrm{C}_{15}+\mathrm{C}_{17}\right) \beta$-amino acids (e) and on iso- $\left(\mathrm{C}_{15}+\mathrm{C}_{17}\right)$ fatty acids (A).

Effect of isoleucine (c) and threonine (d) on anteiso- $\left(\mathrm{C}_{15}+\mathrm{C}_{17}\right) \beta$-amino acids (o) and anteiso- $\left(\mathrm{C}_{15}+\mathrm{C}_{17}\right)$ fatty acids $(\mathbf{A})$.

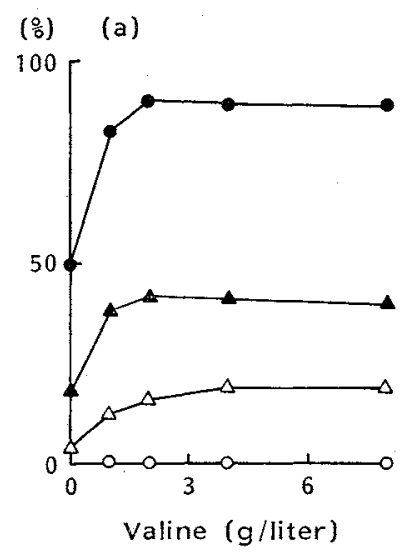

(\%) (c)

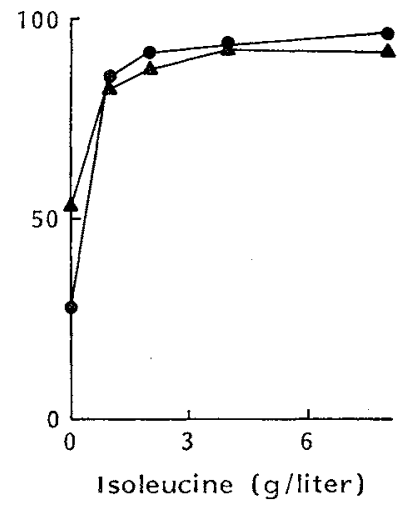

(b)

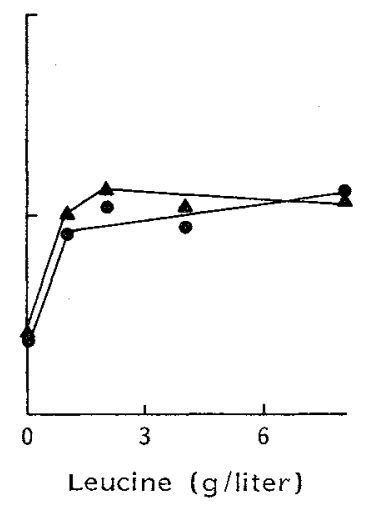

(d)

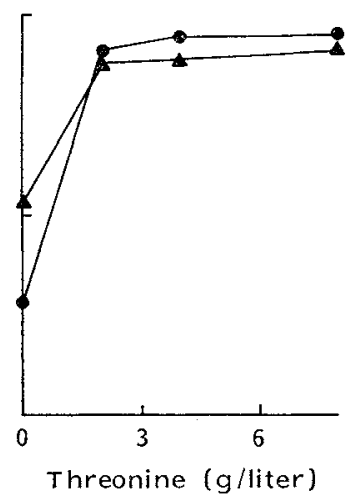


As bacillomycins $\mathrm{F}$ differ only by the nature of the $\beta$-amino acids, the antibiotics obtained in various media were hydrolyzed and the $\beta$ amino acids were analyzed by gas chromatography as described previously ${ }^{4)}$. Table 2 shows the results. Isoleucine and threonine increased odd anteiso $\beta$-amino acids corresponding to bacillomycins $F_{2}$ and $F_{6}$; leucine was less potent in increasing odd iso $\beta$-amino acids corresponding to bacillomycins $F_{1}$ and $F_{5}$; valine increased iso- $\mathrm{C}_{18} \quad \beta$-amino acid corresponding to bacillomycin $\mathrm{F}_{3}$.

As branched amino acids are known to modify the composition of cellular fatty acids of $B$. subtilis ${ }^{7)}$, threonine, valine, leucine and isoleucine can be the precursors of $\beta$-amino acids via fatty acids by dehydrogenation and amination of the corresponding $\beta$-keto acid. Such a hypothesis was tested by analyzing the fatty acid composition of cells grown in various media. Cellular fatty acids were prepared according to the procedure of ITO et al. ${ }^{8)}$ and analyzed by gas chromatography as methyl esters. Fig. 2 compares the effects of the different amino acids on the increased $\beta$-amino acid and on the corresponding fatty acid. Isoleucine and threonine increased at the same level (about 95\%) odd anteiso fatty acids and odd anteiso $\beta$-amino acids, leucine increased odd $i$ so fatty acids and odd iso $\beta$-amino acids (about $55 \%$ for both); valine increased iso- $\mathrm{C}_{14}$ and $\mathrm{C}_{18}$ fatty acids but only $C_{10} \beta$-amino acid, valine did not induce synthesis of $i$ so- $\mathrm{C}_{14} \beta$-amino acid for which no bacillomycins $F$ has previously been identified (Fig. 1).

Thus it appears that if fatty acids are the precursors of $\beta$-amino acids, the enzyme system responsible for $\beta$-amino acid synthesis selects, among the cellular fatty acids, those which correspond to the carbon chain of the $\beta$-amino acids.

Now we are trying to isolate a cell-free system able to synthesize $\beta$-amino acids and to deter- mine whether $\beta$-amino acids are synthesized via fatty acids.

\section{Acknowledgments}

We thank Professor G. Mrchel for stimulating discussions. This work was supported by the Centre National de la Recherche Scientifique (U.A. No. 1176 and PIRMED AIP-ASP "Antibiotiques").

\section{References}

1) Mhammedi, A.; F. Peypoux, F. Besson \& G. MicheL: Bacillomycin F, a new antibiotic of iturin group: Isolation and characterization. J. Antibiotics 35: 306 311, 1982

2) Peypoux, F.; D. Marion, R. Maget-Dana, M. PtaK, B. C. DAS \& G. Michel: Structure of bacillomycin $F$, a new peptidic antibiotic of the iturin group. Eur. J. Biochem. 153: 335 340,1985

3) Besson, F.; F. Peypoux, G. Michel \& L. DELCAMBE: Identification of antibiotics of iturin group in various strains of Bacillus subtilis. J. Antibiotics 31: 284 288, 1978

4) Peypoux, F.; M.-T. Pommier, B. C. Das, F. Besson, L. Delcambe \& G. Michel: Structures of bacillomycin $\mathrm{D}$ and bacillomycin $\mathrm{L}$, peptidolipid antibiotics from Bacillus subtilis. J. Antibiotics 37: 1600 1604, 1984

5) Chevanet, C.; F. Besson \& G. Michel: Effect of various growth conditions on spore formation and bacillomycin L production in Bacillus subtilis. Can. J. Microbiol. 22: 254 258, 1985

6) LANDY, M.; G. H. WARReN, S. B. RosenMaN \& L. G. Colıo: Bacillomycin: An antibiotic from Bacillus subtilis active against pathogenic fungi. Proc. Soc. Exp. Biol. Med. 67: 539 541,1948

7) KANEDA, T.: Fatty acids of the genus Bacillus subtilis. Bacteriol. Rev. 41: 391 418, 1977

8) ITo, M.; K. Aida \& T. UEmURA: Studies of the bacterial formation of peptide antibiotic colistin. Part II. On the biosynthesis of 6methyloctanoic and isooctanoic acids. Agric. Biol. Chem. 33: 262 269, 1969 